\title{
The displacement of structures founded on expansive soils - unapparent causes
}

\author{
Szymon Topoliński ${ }^{1}$, Aleksandra Gorączko ${ }^{1,},{ }^{*}$, Jacek Sztubecki ${ }^{1}$ and Adam Bujarkiewicz ${ }^{1}$ \\ ${ }^{1}$ UTP University of Science and Technology, Faculty of Civil and Environmental Engineering and \\ Architecture, Al. Prof. Kaliskiego 7, 85-796 Bydgoszcz, Poland
}

\begin{abstract}
Determining the causes for the displacement of damaged structures located on expansive soils often requires meticulous and individual analyses of many factors. The sensitivity of the expansive subsoils to environmental changes in humidity, activating its volume changes, requires a careful and comprehensive monitoring of structures susceptible to deformation. The article presents the method of the diagnostics of structures, located on an expansive subsoil in Poland. The methodology and preliminary results of the measurement of the vertical displacements of a building structure founded on expansive subsoil were presented. During field measurements, periodic geodetic measurements of structural displacements were carried out using classical precision levelling and the coordinate method of the Leica TDRA 6000 laser station. At the same time, geotechnical investigations were carried out describing the condition of the ground on which the structure is located. An analysis of the obtained results allowed determining the existing soil and water conditions and drawing unapparent conclusions regarding the causes of damage to the tested structure. On this basis, a further structures monitoring program was established.
\end{abstract}

\section{Introduction}

In the case of the failure analysis of a structure, basing it on expansive soil displacement as a cause is often the first association. This is due to the natural ability of some fine-grained clay-rich soil to change volume under the influence of changes in water content. When the humidity increases, heave caused by swelling can occur. In turn, when drying, shrinkage causing excessive subsidence is inevitable. The fact is, that in many regions of the world, these soils cause innumerable damage and failures of buildings. [1-6].

In a temperate climate zone, the moisture fluctuations in the clay soils are caused by the seasonal and long-term effects of tree roots, during their vegetation or after their removal [7-8]. In addition, factors related to a change of natural water conditions in the subsoil as well as the operation of infrastructure, especially heat pipes, may have a significant impact. In urban areas with a highly developed infrastructure, these are the reasons that should be analyzed in detail [9].

\footnotetext{
* Corresponding author: agora@utp.edu.pl
} 
The article presents the method of diagnostics of structures, located on expansive soil in Bydgoszcz (Poland). The methodology and preliminary results of the measurement of displacements of a investigated construction were presented. On the basis of these results, the actual causes of damage to the diagnosed structure were analysed.

\section{Structure presentation}

\subsection{Construction}

The analysed structure is an overhead (Fig.1), enabling communication between the buildings of the UTP university campus in Bydgoszcz.

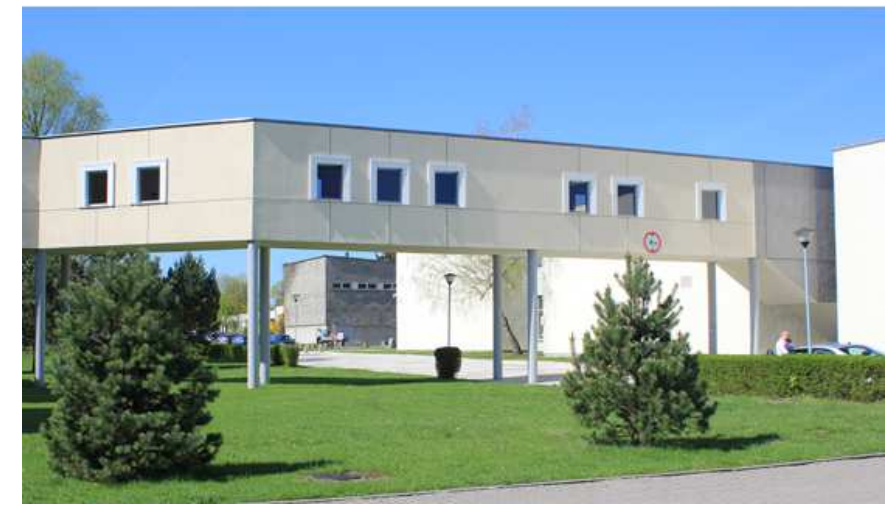

Fig. 1. The investigated structure.

It is a reinforced concrete frame structure supported on 12 pillars. The foundation footings of the columns are monolithically built of reinforced concrete, common for each two neighboring pillars. They are located at various depths: from a maximum of 4.0 m.p.p. from the south to $1.70 \mathrm{~m}$ in p.p.t. for the four central pillars. (the column foundation level is marked on the geotechnical cross-section on figure 3 ).

Since completion of the construction process in 2000-2001, and despite ongoing repairs, it showed increasing damage, the highest in the first years of use. In 2016, the technical condition of the facility was assessed. The largest cracking and delamination was noted on the inner layer made of plasterboard (Fig.2). In the exposed areas, made in the places with the greatest damage to the plasterboard, the reinforced concrete structure (pillars, downstand beams and slabs in the floor level) showed no serious damage. Clearly visible was some horizontal delamination at the junction of the beams with brick wall filling and cracking of the wall structure, both along the joints as well as through the brick. There were also cracks in the ceiling, running over the contacts of the prefabricated slabs. The damages, however, do not endanger the safety of the structure. After repairs that were carried out in 2016, the further development of internal cracks in the plasterboard panels is observed, indicating further work to the structure. In addition, damage was found in the dilatation zone, where the passage way connected to the building both join. 

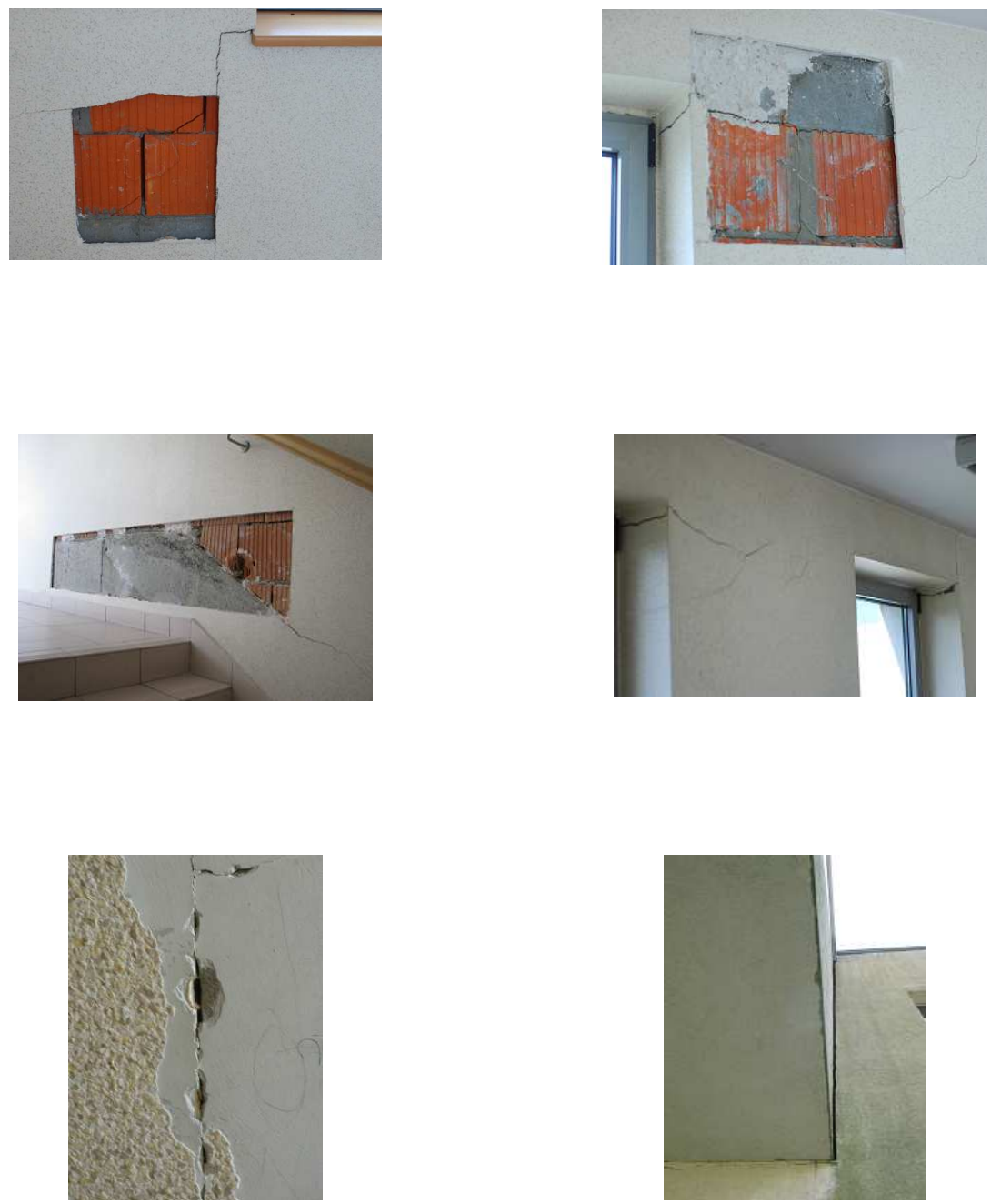

Fig. 2. Damage to the investigated structure.

\subsection{Subsoil}

Analyzing the progress of damage, attention was first drawn to the occurrence of geotechnical reasons. In the foundations level of the overhead expansive clays were found. These are clays representing the geological Poznań series, common for Bydgoszcz subsoil, which are characterized by high expansion (Tab.1). 
Table 1. Parameters and evaluation of expansive clays from the region of Bydgoszcz (after [10]).

\begin{tabular}{lccccc}
\cline { 2 - 5 } $\begin{array}{l}\text { Clays from } \\
\text { Bydgoszcz }\end{array}$ & $\begin{array}{c}\text { Clay } \\
\text { content }\end{array}$ & $\begin{array}{c}\text { Plasticity } \\
\text { Index }\end{array}$ & $\begin{array}{c}\text { Swell } \\
\text { Index }\end{array}$ & $\begin{array}{c}\text { Swelling } \\
\text { pressure }\end{array}$ & $\begin{array}{c}\text { Expansivity } \\
\text { acc. to [11] }\end{array}$ \\
\cline { 2 - 6 } & $\mathbf{f}_{\mathbf{i}}[\%]$ & $\mathbf{I}[\%]$ & $\square \mathbf{P}[\%]$ & $\mathbf{p}_{\mathbf{c}}[\mathrm{MPa}]$ & \\
\hline $\begin{array}{l}\text { Average } \\
\text { value }\end{array}$ & $\mathbf{4 9}$ & $\mathbf{5 8}$ & $\mathbf{2 9}$ & $\mathbf{0 , 3 8}$ & High \\
\hline $\begin{array}{l}\text { Min-Max } \\
\text { values }\end{array}$ & $30-84$ & $30-99$ & $5-57$ & $0,07-1,9$ & $\begin{array}{c}\text { medium - } \\
\text { - very.high }\end{array}$ \\
\hline $\begin{array}{l}\text { Number } \\
\text { Of samples }\end{array}$ & 888 & 1577 & 16 & 14 & \\
\hline
\end{tabular}

S

GEOTECHNICAL CROSS-SECTION I-I

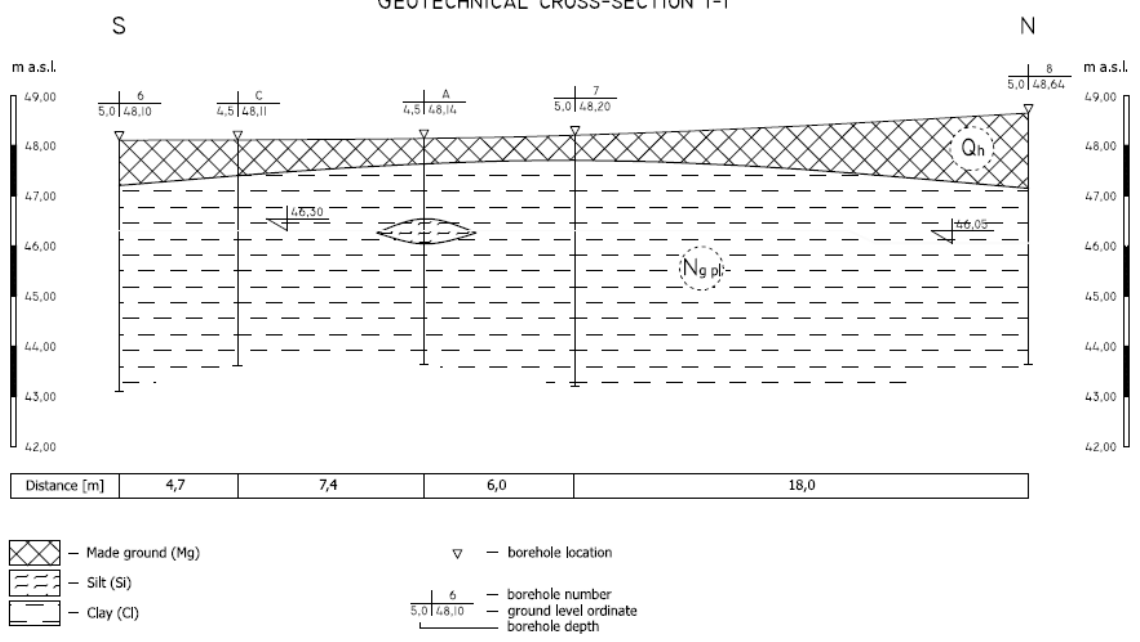

Fig. 3. Profile of subsoil under the overhead passage.

The reasons for damage to the construction, in relation to the expansive subsoil, were derived from the fact that dozens of poplars grew under the passage. As research, which was carried out a few years from construction has shown, poplars could cause local shrinkage and settlements of the ground, due to the low water content of expansive clay. The trees were then prophylactically removed. In addition, there is a water supply and sewerage network near the foundation of the passage, which could have an influence on the moisture in subsoil.

\section{Geodetic monitoring}

In order to unequivocally investigate the influence of the subsoil and to determine the actual displacements of the structure, systematic geodetic monitoring of the facility was initiated in July 2017.

The monitoring of both vertical displacements of supports as well as the vertical and horizontal displacements of the basic structure of the passage is foreseen. The arrangement of the supports is shown in figure 4. 


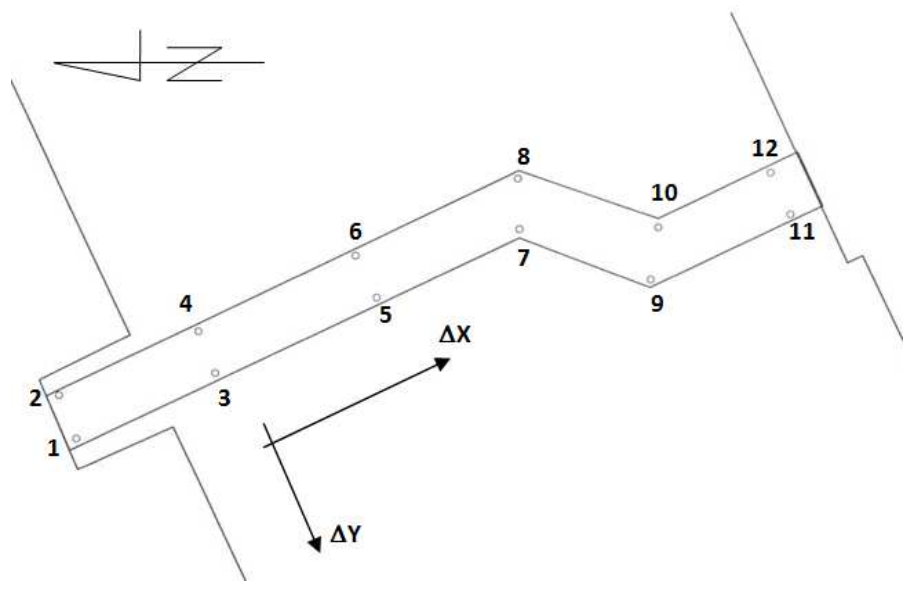

Fig. 4. Scheme of the arrangement of the structural supports.

The determination of vertical displacements of the structural supports was performed by precise leveling (using the Ni007 leveling tool). In order to carry out the research, a control network consisting of 15 benchmarks was set up. Benchmarks 1, 3-12 were placed at the bottom of the columns (Fig. 5) and the remaining ones, constituting a set of reference points, on stable neighboring buildings.
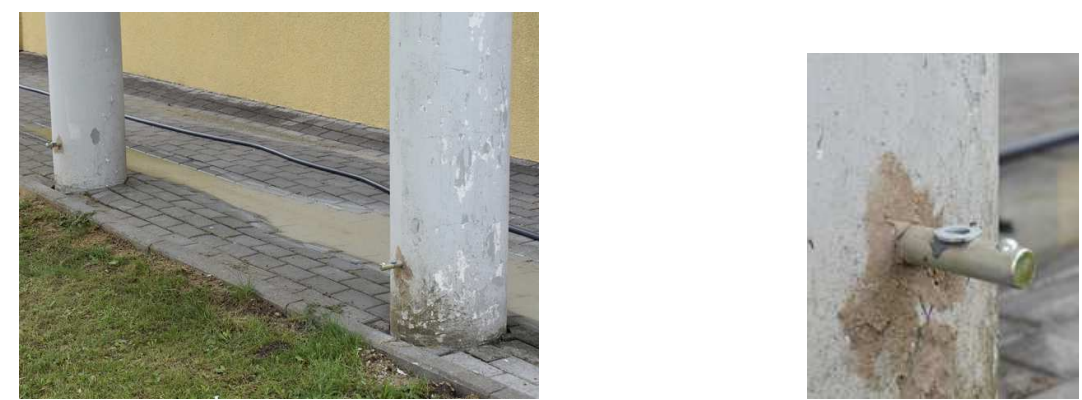

Fig. 5. External benchmarks.

To obtain a full view of geometric changes to the construction, the control points were also stabilized on the floor inside the passage and in the buildings connected to it. Points inside are fastened to the floor in places of a connection with the supports. The network of points created in this way allows the monitoring of the spatial work of the entire structure.

The Leica TDRA6000 coordinate laser station was used to measure the network, using a precise measurement in the 1.5 "RRR prism mode, which makes it possible to determine displacements of the control points with an accuracy of $0.2 \mathrm{~mm}$, which makes it an excellent tool for monitoring engineering structures [13]. The applied method allowed determining the values of the horizontal and vertical displacements of this network, and the vertical components can also be compared with vertical displacements of the external benchmarks.

Four network measurements were carried out (Table 2). They were made in optimal conditions, minimizing the influence of weather factors on the accuracy of the measurements. 
Table 2. The times of the measurements.

\begin{tabular}{|c|c|c|}
\hline No. meas. & Date & Temp. \\
\hline 0 & 2017.07 .21 & $23^{\circ} \mathrm{C}$ \\
\hline 1 & 2017.09 .04 & $14^{\circ} \mathrm{C}$ \\
\hline 2 & 2017.11 .10 & $6^{\circ} \mathrm{C}$ \\
\hline 3 & 2018.03 .10 & $3{ }^{\circ} \mathrm{C}$ \\
\hline
\end{tabular}

From each of the measurements, the vertical displacements of the benchmarks located in the lower part of the columns (Table 3) and the values of the displacements of the structure's floor were obtained (Table 4).

Table 3. Vertical Displacements of points at the bases of the support pillars in reference to Measurement 0 .

\begin{tabular}{|c|c|c|c|c|c|c|}
\hline \multirow{2}{*}{ Benchmark } & \multicolumn{2}{|c|}{ Meas. 0 - Meas. 1 } & \multicolumn{2}{c|}{ Meas. 0 - Meas. 2 } & \multicolumn{2}{c|}{ Meas. 0 - Meas. 3 } \\
\cline { 2 - 7 } & $\mathbf{d Z ~}[\mathbf{m m}]$ & $\mathbf{m}_{\mathbf{d Z}}[\mathbf{m m}]$ & $\mathbf{d Z}[\mathbf{m m}]$ & $\mathbf{m}_{\mathbf{d Z}}[\mathbf{m m}]$ & $\mathbf{d Z}[\mathbf{m m}]$ & $\mathbf{m}_{\mathbf{d Z}}[\mathbf{m m}]$ \\
\hline 1 & $-0,33$ & 0,03 & $-0,50$ & 0,04 & $-0,05$ & 0,09 \\
\hline 2 & - & - & - & - & - & - \\
\hline 3 & $-0,30$ & 0,02 & $-0,36$ & 0,03 & $-0,21$ & 0,06 \\
\hline 4 & $-0,25$ & 0,03 & $-0,42$ & 0,04 & $-0,25$ & 0,08 \\
\hline 5 & $-0,64$ & 0,03 & $-0,46$ & 0,04 & $-0,32$ & 0,08 \\
\hline 6 & $-0,56$ & 0,03 & $-0,35$ & 0,05 & $-0,27$ & 0,10 \\
\hline 7 & $-0,35$ & 0,04 & 0,12 & 0,05 & 0,81 & 0,11 \\
\hline 8 & $-0,24$ & 0,04 & 0,31 & 0,05 & 1,13 & 0,11 \\
\hline 9 & 0,12 & 0,03 & 0,71 & 0,04 & 0,99 & 0,10 \\
\hline 10 & 0,13 & 0,02 & 0,74 & 0,03 & 1,08 & 0,07 \\
\hline 11 & 0,06 & 0,03 & 0,36 & 0,04 & 0,45 & 0,08 \\
\hline 12 & $-0,08$ & 0,03 & 0,18 & 0,04 & 0,26 & 0,09 \\
\hline
\end{tabular}

Table 4. Vertical displacements of points on the floor of the overhead passage in reference to measurement 0 .

\begin{tabular}{|c|c|c|c|c|c|c|}
\hline \multirow{2}{*}{$\begin{array}{c}\text { Meas. } \\
\text { Point }\end{array}$} & \multicolumn{2}{|c|}{ Meas. 0 - Meas. 1 } & \multicolumn{2}{c|}{ Meas. 0 - Meas. 2 } & \multicolumn{2}{c|}{ Meas. 0-Meas. 3 } \\
\cline { 2 - 7 } & $\mathbf{d Z}[\mathbf{m m}]$ & $\mathbf{m} \mathbf{d Z}[\mathbf{m m}]$ & $\mathbf{d Z}[\mathbf{m m}]$ & $\mathbf{m} \mathbf{d Z}[\mathbf{m m}]$ & $\mathbf{d Z}[\mathbf{m m}]$ & $\mathbf{m}_{\mathbf{d Z}}[\mathbf{m m}]$ \\
\hline 1 & 0,15 & 0,07 & $-0,19$ & 0,06 & $-0,58$ & 0,07 \\
\hline 2 & 0,08 & 0,07 & $-0,17$ & 0,06 & $-0,43$ & 0,07 \\
\hline 3 & $-0,05$ & 0,07 & $-0,99$ & 0,07 & $-1,83$ & 0,07 \\
\hline 4 & $-0,09$ & 0,07 & $-1,13$ & 0,07 & $-1,76$ & 0,07 \\
\hline 5 & $-0,13$ & 0,08 & $-1,21$ & 0,07 & $-1,89$ & 0,08 \\
\hline 6 & $-0,22$ & 0,08 & $-1,23$ & 0,07 & $-1,89$ & 0,08 \\
\hline 7 & $-0,01$ & 0,08 & $-0,69$ & 0,07 & $-0,90$ & 0,08 \\
\hline 8 & 0,17 & 0,08 & $-0,50$ & 0,07 & $-0,55$ & 0,08 \\
\hline 9 & $-0,07$ & 0,07 & $-0,67$ & 0,07 & $-0,85$ & 0,07 \\
\hline 10 & 0,06 & 0,07 & $-0,49$ & 0,07 & $-0,66$ & 0,07 \\
\hline 11 & 0,03 & 0,07 & $-0,36$ & 0,06 & $-0,66$ & 0,07 \\
\hline 12 & $-0,18$ & 0,07 & $-0,59$ & 0,06 & $-0,94$ & 0,07 \\
\hline
\end{tabular}

The values of the vertical displacements of the supports in the studied period were from $-0.64 \mathrm{~mm}$ to $1.33 \mathrm{~mm}$ (Table 2); showing both a slight settlement and raising of the supports. It can be noticed that the results of the displacements of the ground part of the columns are not clearly related to the results of the vertical displacements of the main structure, which were determined on the basis of measurements points stabilized on its floor. This difference most probably results, among others, from the change in column length caused by the temperature changes in the following measurements. 
The values of the horizontal control points displacements placed on the floor (Table 5.) should also be taken into account in order to fully assess the spatial work of the construction.

Table 5. Horizontal displacements of points on the floor of the overhead passage in reference to measurement 0 .

\begin{tabular}{|c|c|c|c|c|c|c|}
\hline \multirow{2}{*}{$\begin{array}{c}\text { Meas. } \\
\text { Point }\end{array}$} & \multicolumn{2}{|c|}{ Meas. 0-Meas. 1 } & \multicolumn{2}{c|}{ Meas. 0- Meas. 2 } & \multicolumn{2}{c|}{ Meas. 0-Meas. 3 } \\
\cline { 2 - 7 } & $\mathbf{d X}[\mathbf{m m}]$ & $\mathbf{d Y}[\mathbf{m m}]$ & $\mathbf{d X}[\mathbf{m m}]$ & $\mathbf{d Y}[\mathbf{m m}]$ & $\mathbf{d X}[\mathbf{m m}]$ & $\mathbf{d Y}[\mathbf{m m}]$ \\
\hline 1 & 0,45 & 0,94 & 0,50 & 0,30 & 0,97 & $-0,07$ \\
\hline 2 & 0,44 & 0,86 & 0,72 & 0,06 & 1,17 & $-0,40$ \\
\hline 3 & 0,17 & 1,18 & 0,14 & $-0,41$ & 0,23 & $-0,83$ \\
\hline 4 & 0,24 & 1,13 & 0,31 & $-0,58$ & 0,38 & $-1,01$ \\
\hline 5 & $-0,35$ & 0,77 & $-0,82$ & $-0,66$ & $-1,51$ & $-1,78$ \\
\hline 6 & $-0,34$ & 0,66 & $-0,81$ & $-0,82$ & $-1,27$ & $-1,99$ \\
\hline 7 & $-0,87$ & 0,19 & $-1,81$ & $-1,37$ & $-2,74$ & $-2,54$ \\
\hline 8 & $-0,83$ & 0,11 & $-1,67$ & $-1,50$ & $-2,64$ & $-2,78$ \\
\hline 9 & $-1,57$ & 0,19 & $-2,71$ & $-1,21$ & $-3,60$ & $-1,90$ \\
\hline 10 & $-1,69$ & 0,14 & $-2,80$ & $-1,23$ & $-3,94$ & $-1,84$ \\
\hline 11 & $-1,90$ & 0,28 & $-3,25$ & $-0,10$ & $-4,66$ & 0,01 \\
\hline 12 & $-2,09$ & 0,13 & $-3,56$ & $-0,34$ & $-5,04$ & $-0,31$ \\
\hline
\end{tabular}

The horizontal displacement was determined in accordance with the coordinate system shown in Fig. 4, in which the $\mathrm{X}$ axis is defined in parallel and the axis $\mathrm{Y}$ is perpendicular to the axis of the investigated structure.

Horizontal observation values along the $\mathrm{X}$ axis indicate a shortening of the construction which is consistent with the ever lower temperature (Table 2) observed during the following measurements. It can be noticed that the connector unevenly moves away from neighboring buildings, as indicated by the $\mathrm{dX}$ displacements for points 1 and $12(+0.97 \mathrm{~mm}$ and $-0.54 \mathrm{~mm}$ respectively).

Movements of the control points observed along the $\mathrm{Y}$ axis, on the other hand, indicate that the passage is bulging.

\section{Discussion and Conclusions}

Damage to the structure, which have appeared from the beginning of its exploitation and inventoried in 2016, has been associated with the diversified settlement of the supports, resulting from the movements of the expansive subsoil. Clays, which are dried by the roots of trees, and undergoing as a result the shrinkage, may cause the uneven settlements of the foundations. In our climate zone, the influence of tree roots is one of the most common causes of excessive clay shrinkage in the foundation area. After the removal of trees from the immediate vicinity of the investigated structure, which took place after several years of use (around 2010), the water content of clay in the subsoil can return to the original value.

Currently, after renovation carried out in 2016, newly occurring cracks indicate further displacements and deformations of the structure. Damage is not large, nevertheless it requires careful monitoring and reconsidering the reasons for its occurrence. The presented measurements showed a few millimeter displacements, however, they were not related to changes in the volume and movements of the expansive subsoil. Displacements of the support pillars are much smaller and do not correlate with movements of the overhead passageway. This indicates the construction susceptibility to thermal or wind deformations. 
The study was supported by RCI Laboratories: Laboratory of Expansive Soil Research and Geodetic Laboratory for Inventory and Analysis of Engineering Structures, at the UTP University of Science and Technology in Bydgoszcz, Faculty of Civil and Environmental Engineering and Architecture

\section{References}

1. A.A. Al-Rawas, M. Qamaruddin, Build. Environ., 33(2), 159-171 (1998).

2. F.G. Bell, R.R. Maud, Env. \& Eng. Geosci., 1(1), 41-59, (1995).

3. D.G. Fredlund, Develop. in Soil Sci., 24, 499-524 (1996).

4. R.L. Meehan, L.B. Karp, J. Perform. Constr. Fac., 8(2), 139-157(1994).

5. L.D. Jones, I. Jefferson, Expansive soils. (ICE Publishing, 2012).

6. J. Nelson, , D. J. Miller, Expansive soils: problems and practice in foundation and pavement engineering. (John Wiley \& Sons, 1997).

7. P.G. Biddle, ASCE Geot. Spec. Publ. No.116, 1-23, (2001).

8. R. Driscoll, Geotechnique, 33, 93-105, (1983).

9. J. Przystański [ed.], Wyd. Polit. Pozn, Rozprawy, 244, (1991).

10. A. Gorączko, M.K. Kumor, Biul. PIG, 446 (2), 305-314, (2011).

11. A. Niedzielski, Rocz. AR w Poznaniu, Rozprawy Nauk., 238, 99. (1993).

12. A. Gorączko, Phd Thesis. UTP University of Scince and Technology, 123, (2007).

13. J. Sztubecki, A. Bujarkiewicz, M. Sztubecka, CEER, 23(4), 145-160, (2016). 